\title{
Microstructure and texture evolution in multi-pass warm rolled AZ31 magnesium alloy
}

\author{
Di Liu ${ }^{\mathrm{a}}$ and Zuyan Liu \\ National Key Laboratory for Precision Hot Processing of Metals, Harbin Institute of Technology, China
}

\begin{abstract}
Electron Backscatter Diffraction (EBSD) is employed to characterize the microstructure and texture established during the process of warm rolled AZ31 magnesium alloy sheets. The grain size was refined from $17.4 \mu \mathrm{m}$ to $3.8 \mu \mathrm{m}$ after 4 pass rolling. Texture of as-rolled sheets was expressed by (0002) basal texture, and the texture intensity was increased with the rolling pass increasing. The mechanical properties of as-rolled sheets were greatly improved by warm rolling.
\end{abstract}

\section{Introduction}

Magnesium alloys have attracted significant interest due to their excellent specific properties and low weight which make these materials potentially suitable for applications in automotive, aerospace and electronic industries [1]. Unfortunately, $\mathrm{Mg}$ alloy sheets usually exhibit poor ductility at room temperature which is a significant impediment to their acceptance in industrial applications [2]. It is well known that grain refinement has a great influence on the improvement of mechanical properties of AZ31 magnesium alloys [2-4]. It was reported [5] that mechanical properties of AZ31 magnesium alloys were enhanced when the grain size was reduced from $9.8 \mu \mathrm{m}$ to $1.4 \mu \mathrm{m}$. On the other hand, basal texture is another important factor which can greatly influence the mechanical properties of magnesium alloys. Agnew et al. [6,7] indicated that the ductility of AZ31 and AZ80 magnesium alloys was greatly enhanced due to texture modification during equal channel angular extrusion (ECAE). In this work, the relationship between microstructure, texture and mechanical properties of AZ31 magnesium alloys by multi-pass pass warm rolling were studied.

\section{Experimental}

The AZ31 magnesium alloy sheets used in this study were obtained by hot rolling. The chemical composition of the material is $\mathrm{Mg}-2.85 \% \mathrm{Al}-0.95 \% \mathrm{Zn}$ (in mass percent). The dimensions of samples prepared for investigation amount to $120 \mathrm{~mm}$ width $\times 4 \mathrm{~mm}$ thick $\times 100 \mathrm{~mm}$ length. Microstructure characterization of the initial material is shown in Fig. 1, including the inverse pole figure (IPF) map, misorientation angle distribution and $\{0002\}$ pole figure. The average grain size of the initial sheet was

\footnotetext{
${ }^{a}$ Corresponding author: liudi_hit@126.com
}

This is an Open Access article distributed under the terms of the Creative Commons Attribution License 4.0, which permits unrestricted use, distribution, and reproduction in any medium, provided the original work is properly cited. 


\section{MATEC Web of Conferences}
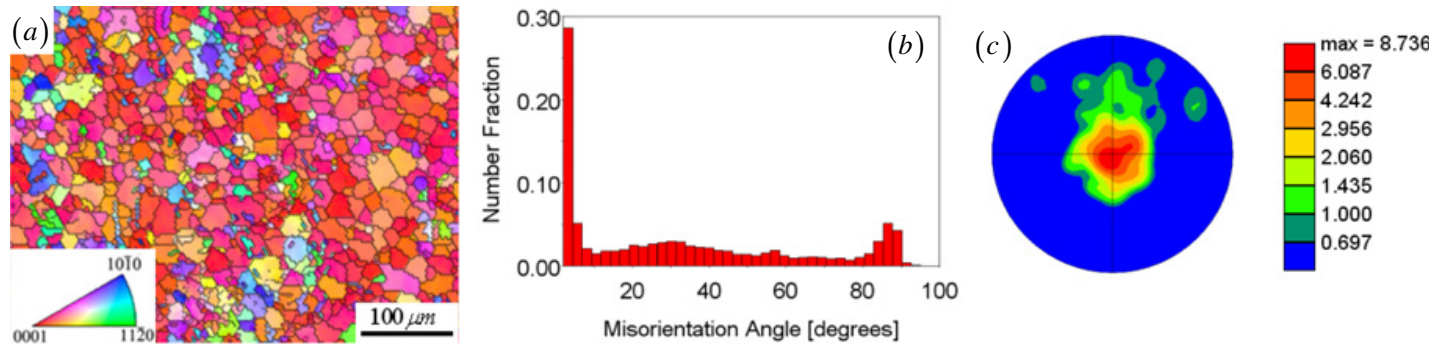

Figure 1. Microstructural characteristics of initial AZ31 magnesium alloy sheet: (a) inverse pole figure map; (b) misorientation angle map and (c) $\{0002\}$ pole figure.

$17.4 \mu \mathrm{m}$. Fewer $\{10-12\}\langle-1011\rangle$ tension twins were observed leading to a local peak at about $86^{\circ}$ in the misorientation angle map.

The as-rolled AZ31 magnesium alloy sheets were subjected to warm rolling at a given thickness reduction of $40 \%$ per pass. And the sheet was rolled to $0.5 \mathrm{~mm}$ through 4 passes. Rolling mill of $220 \mathrm{~mm}$ in diameter was used in this study. The temperature of the rollers was $523 \mathrm{~K}$ and the temperature of the sheet was at room temperature in each pass. The rolling was performed at a constant rotation speed of $5 \mathrm{~m} / \mathrm{min}$, and the as-rolled sheets were cooled in the air atmosphere.

Tensile specimens with a gauge length of $25 \mathrm{~mm}$ and width of $6 \mathrm{~mm}$ were machined out of the samples along both RD and TD. Tensile tests were performed at room temperature using Instron 5569 testing machine at an initial strain rate of $10^{-3} \mathrm{~s}^{-1}$. To check the repeatability of the results, three experiments were conducted under each set of conditions.

The microstructure and texture of the sheets were identified using electron backscattered diffraction (EBSD) performed on a scanning electron microscope (SEM, Quanta 200 FEG-SEM) equipped with an EBSD detector and OIM 6.14 analysis system. Surface preparation of the samples consisted of grinding with SiC emery papers of \#200, \#600, \#800 and electrolytically polishing with solution of phosphoric acid and ethanol with a 3:5 volume ratio. Because of the gradient in microstructure between the inner and outer surfaces of the sheets, all measurements were restricted to the centres of the sections.

\section{Results and discussion}

\subsection{Microstructure}

The microstructure of the as-rolled sheets obtained by EBSD in the RD-TD plane with the normal direction corresponding to the crystal reference system of each pass are shown in Fig. 2(a)-(d). The grain size distribution and variation of the average grain size at each pass are shown in Fig. 2(e) and (f), respectively. The initial AZ31 magnesium alloy sheet has coarse grains ranging from $2 \mu \mathrm{m}$ to $36 \mu \mathrm{m}$. After a single pass rolling, the grains were greatly refined with an average grain size changed from $17.4 \mu \mathrm{m}$ to $5 \mu \mathrm{m}$. A proportion of new recrystallization grains appeared along the deformed grain boundaries. The average grain size was reduced to $3.5 \mu \mathrm{m}$ after 2 passes of rolling, and the microstructure was mainly consisted of recrystallization grains. The further rolling passes caused a slight increase of the average grain size to $3.8 \mu \mathrm{m}$, finally, homogenous and equiaxed grains were obtained.

\subsection{Texture evolution}

The $\{0002\}$ pole figures of each pass obtained from the EBSD data in the RD-TD plane are shown in Fig. 3. The as-rolled sheets of each pass posses a strong basal texture and the orientation distribution 

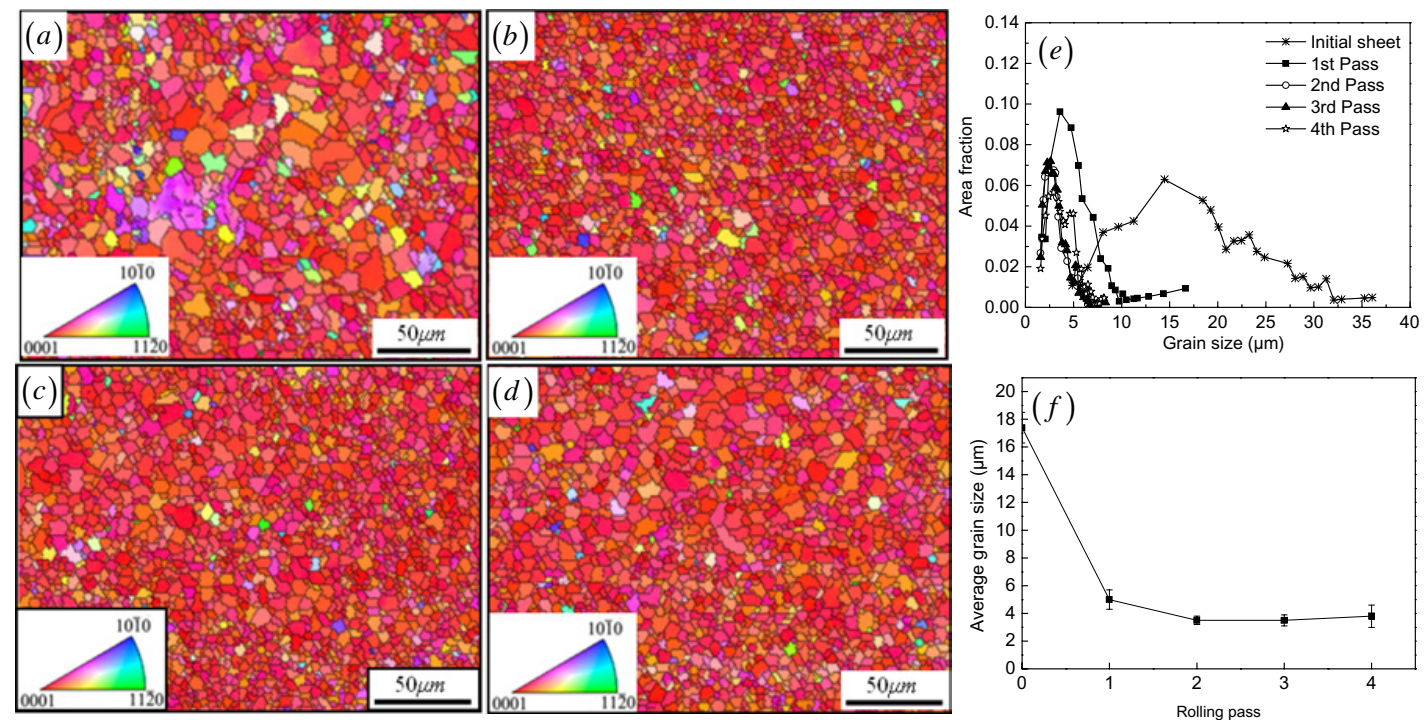

Figure 2. IPF map of the as-rolled AZ31 magnesium alloy sheets at each pass, (a)-(d) for 1-4 pass, (e) grain size distribution before and after warm rolling and (f) average grain size of each pass.
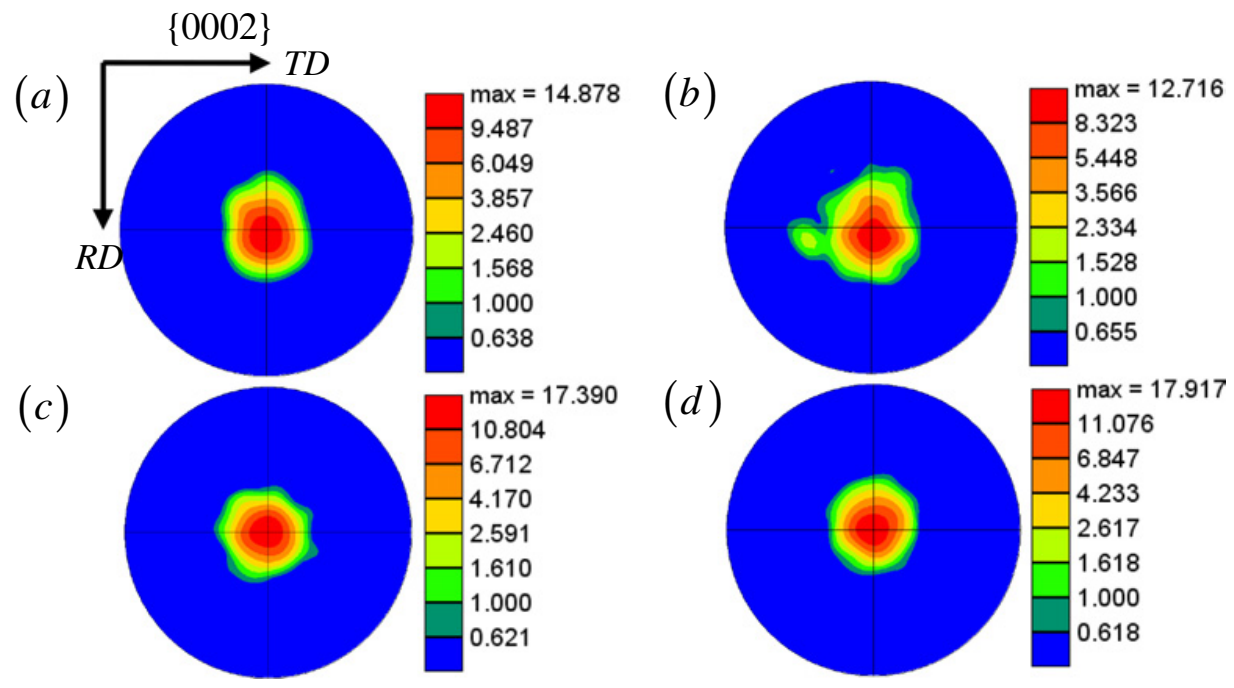

Figure 3. $\{0002\}$ pole figures of AZ31 as-rolled sheets of each pass, (a)-(d) for 1-4 pass.

around the normal direction is wider in RD than in TD. Researchers have found that a combination of basal $\langle a\rangle$ slip and tensile twinning was responsible for the strong basal texture in as-rolled AZ31 sheets [8]. Furthermore, it has been proved that pyramidal $\langle c+a\rangle$ slip is responsible for the basal pole splitting towards RD [9]. The texture intensity was increased with the increase of rolling passes as a whole, and the basal texture intensity of 2 rd passes was the lowest. 

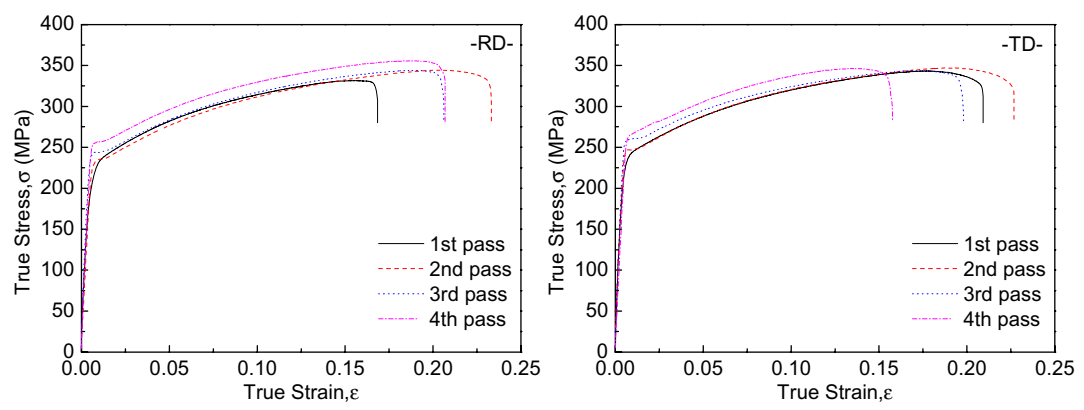

Figure 4. Room-temperature stress-strain curves for AZ31 Mg alloy sheets rolled in different rolling passes.
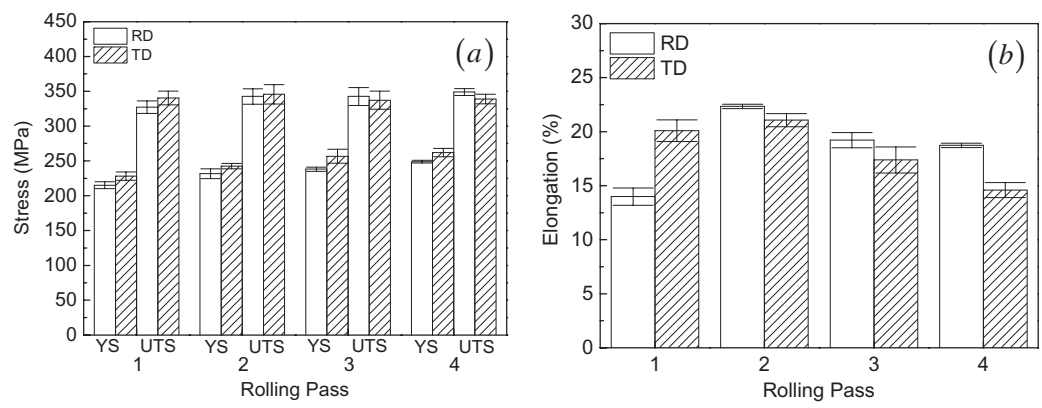

Figure 5. Variation of the strengths and elongations of as-rolled AZ31 Mg alloy sheets in different rolling passes (a) yield strength and ultimate tensile strength and (b) elongation.

\subsection{Mechanical properties}

The room-temperature stress-strain curves of the as-rolled AZ31 Mg alloy sheets along RD and TD are presented in Fig. 4. Figure 5 shows the variations of yield strength, ultimate tensile strength and elongation of as-rolled AZ31 Mg alloy sheets in different rolling passes. The strength along TD was better than that along RD. The anisotropic behaviour of the as-rolled AZ31 magnesium alloy sheets is mainly the result of texture. Kaiser et al. [10] studied the relationship between anisotropic properties of AZ31 magnesium alloy sheets and indicated that the distribution of the $\{0002\}$ basal plane has a significant influence on the anisotropy of the sheet.

The grains were greatly refined due to the warm rolling and the grain size was reduced from $17.4 \mu \mathrm{m}$ to $3.8 \mu \mathrm{m}$ (Fig. 2). At the same time, the as-rolled sheets exhibited strong basal texture. The yield strength of the as-rolled sheets was increased with the rolling pass increased indicated that grain refinement and texture strengthening are both beneficial for the enhancement of strengthen.

From Fig. 5(b), the elongation of the as-rolled sheets reached a maximum value of $23 \%$ along RD after 2 passes rolling with a weaker texture and refined grain size. Guo et al. [11] studied the effects of texture on mechanical properties via conventional hot rolling (CFR) and differential speed rolling (DSR) and concluded that texture may have more significant effect on the ductility of AZ31 alloy than grain size at room temperature. Wang et al. [12] analyzed the mechanical properties of ZK60 magnesium alloy by hot rolling, and the results suggested the enhancement of strength was most attributed to both grain refinement and basal texture hardening. In contrast, the effect of grain refinement on the ductility is also beneficial, but the concentration of basal texture goes against ductility improvement. Hence, the improvement of elongation was ascribed to grain refinement and weak texture and the effect of texture has more obvious influence on the elongation of AZ31 magnesium alloys. 


\section{ICNFT 2015}

\section{Conclusions}

The grains are greatly refined in the process of warm rolling. The yield strength of as-rolled sheets is enhanced due to both grain refinement strength and texture strength. On the other hand, the grain refinement also has a positive influence on the strengthen elongation, but the enhancement of texture intensity goes against the elongation improvement.

\section{References}

[1] B.L. Mordike, T. Ebert. Mater. Sci. Eng. A. 302 (2001) 37-45

[2] T. Mukai, M. Yamanoi, H. Watanabe, K. Higashi. Scripta Mater. 45 (2001) 89-94

[3] A. Jain, O. Duygulu, D.W. Brown, C.N. Tomé, S.R. Agnew. Mater. Sci. Eng. A. 486 (2008) 545-555

[4] A. Yamashita, Z. Horita, T.G. Langdon. Mater. Sci. Eng. A. 300 (2001) 142-147

[5] Q. Yang, A. Ghosh. Acta Mater. 54 (2006) 5159-5170

[6] S.R. Agnew, J.A. Horton, T.M. Lillo, D.W. Brown. Scripta Mater. 50 (2004) 377-381

[7] P. Mehrotra, T. Lillo, S. Agnew. Scripta Mater. 55 (2006) 855-858

[8] A. Styczynski, C. Hartig, J. Bohlen, D. Letzig. Scripta Mater. 50 (2004) 943-947

[9] H. Yan, R.S. Chen, E.H. Han. Mater. Sci. Eng. A. 527 (2010) 3317-3322

[10] F. Kaiser, D. Letzig, J. Bohlen, A. Styczynski, C. Hartig, K.U. Kainer. Mater Sci Forum. 419 (2003) 315-320

[11] L.L. Guo, Z.C. Chen, L. Gao. Mater. Sci. Eng. A. 528 (2011) 8537-8545

[12] X. Wang, W.Z. Chen, L.X. Hu, G.J. Wang, E.D. Wang. Trans. Nonferrous Met. Soc. China. 21 (2011) 242-246 